\title{
Mindfulness meditation training in an occupational setting: Effects of a 12-weeks mindfulness-based intervention on wellbeing
}

\author{
Teresa Fazia ${ }^{\mathrm{a}, *, 1}$, Francesco Bubbico ${ }^{\mathrm{a}, 1}$, Giovanni Berzuini ${ }^{\mathrm{a}}$, Laura Dalla Tezza ${ }^{\mathrm{a}}$, \\ Carolina Cortellini $^{\mathrm{b}}$, Salvatore Bruno ${ }^{\mathrm{c}}$ and Luisa Bernardinelli ${ }^{\mathrm{a}}$ \\ ${ }^{a}$ Department of Brain and Behavioral Sciences, University of Pavia, Pavia, Italy \\ ${ }^{\mathrm{b}}$ Microdata Group srl, Cremona, Italy \\ ${ }^{\mathrm{c}}$ Istituto di Psicosintesi, Milan, Italy
}

Received 6 April 2021

Accepted 8 July 2021

\begin{abstract}
.
BACKGROUND: Mindfulness-based interventions (MBIs) are known for their beneficial effects on positive and negative psychological factors. When applied in an occupational context, MBIs might help workers to cope with stress, increase their professional outcomes and wellbeing.

OBJECTIVE: In this two-groups pre-post experimental design we tested the effect of our MBI, called Integral Meditation (IM), among the employers of an Italian service company by measuring positive and negative aspects of psychological wellbeing related to mindfulness and workplace functioning through eight self-report questionnaires (CORE-OM, FFMQ, WEMWBS, MAIA, PSS, PANAS, STAI-X1, SCS).

METHOD: Forty-two voluntary non-clinical employers of the company, randomly assigned to the experimental or the control group, were analyzed. The experimental group underwent our IM program, which consists of 12 weekly meditation classes given after the afternoon shift, while the control group did not receive any intervention. Data was analyzed via linear mixed models.

RESULTS: Statistically significant results were obtained for FFMQ observing subscale ( $\beta=0.49, p=0.014)$, WEMWBS $(\beta=5.31, p=0.02)$, PSS $(\beta=-3.31, p=0.03)$, the whole scale of SCS $(\beta=0.47, p=0.01)$ and self-judgment $(\beta=0.68$, $p=0.003)$ and isolation $(\beta=-0.66, p=0.01)$ SCS subscales. Statistically significant results were also found in four out of eight subscales of MAIA: emotional awareness $(\beta=1.26, p<0.001)$, self-regulation $(\beta=1.28, p<0.001)$, body listening $(\beta=1.08, p<0.001)$ and trusting $(\beta=1.1, p<0.001)$.

CONCLUSION: Our intervention has demonstrated to bring beneficial effects in a mindfulness subdomain, in perceived stress, self-compassion, interoception and psychological wellbeing. Based on our results, we conclude that our intervention was effective in increasing the positive aspects of wellbeing and in reducing stress.
\end{abstract}

Keywords: Mindfulness-based interventions, healthy subjects, psychological wellbeing, questionnaires, workplace

\footnotetext{
${ }^{1}$ These authors contributed equally to this work.

*Address for correspondence: Teresa Fazia, Department of Brain and Behavioral Science, University of Pavia, Via Bassi 21,
}

27100 Pavia, Italy. Tel.: +390382987188; E-mail: teresa.fazia01@ ateneopv.it; Orcid 0000-0002-9577-8450. 


\section{Background}

Psychological factors such as mental wellbeing and emotion regulation have an impact on people's quality of life as well as on their capacity and productivity as workers. For such reasons employees' mental health should converge the interests of the companies, the public health and the workers themselves. Since mental issues lower people's quality of life [1] and they come with economic burden on private companies as well as on societies [2, 3], psychological preventive interventions represent an important tool to avoid those costs. Moreover, work performance is not only affected by but it also often causes mental issues, such as burnout or work-related stress, which in turn are associated with a variety of other physical and mental issues $[4,5]$.

Over the last decades, mindfulness-based interventions (MBIs) have gained much interest since they have been proved to be effective in reducing mental health symptoms and in increasing mental wellbeing in clinical and non-clinical populations. Moreover, MBIs might be easily applied in different settings and they are nowadays being integrated in many institutional environments like schools, military, prisons, workplaces [6]. For example, companies like Google, Aetna, and General Mills are offering employees mindfulness training [7].

Empirical research on the impact of mindfulness in the workplace settings has accelerated [8-10]. Emerging literature supports the hypothesis that mindfulness is related to a better workplace functioning [11] and MBIs seem to produce benefits on an array of psychological variables. Hilton et al. [12] presented an evidence map study which indicated that MBI when applied in workplaces might have a positive impact on chronic illness, pain, substance use, depression, anxiety and perceived stress among others. The authors of this evidence map study noticed that MBIs have been applied to a large range of clinical indications, but many areas are still based on only a small number of robust research studies.

An inclusive systematic review [13] of 147 studies conducted in occupational settings reported clear beneficial effects of MBIs on physical health, mindfulness, anxiety and stress. They also found that mindfulness and mindfulness interventions were associated with increased wellbeing in other domains such as job satisfaction, job performance, empathy and compassion.

On his meta-analysis (N. studies $=19$ ) Virgili [14] claimed MBIs to be more effective than other sim- ilar stress management interventions, such as yoga and relaxation for reducing psychological distress in working adults and that effects obtained at posttreatment were largely maintained at follow-up. He also reported that the effects of MBIs don't vary significantly through different kinds of employees, despite most of the data being obtained among healthcare professionals. Another review [15] reported that the types of job most commonly associated with mindfulness-based studies are those in the healthcare sector.

The aim of the current study is to investigate our a priori hypothesis of the causal beneficial effects of our MBI applied in an organizational context on psychological indicators measured by eight self-report questionnaires encompassing different domains of positive and negative aspects of wellbeing.

\section{Methods}

\subsection{Study design}

Participants were recruited from the employers of a consulting company located in Italy. This consulting company has above 300 employers and it provides services mainly related to data management. The owner of the company responded positively to our proposal and offered to their employees the possibility to join our research freely. No exclusion criteria were applied except current experience of serious mental or physical health problems that would affect the ability to engage with the course. No subjects were excluded based on the above criteria. A total of 59 subjects were recruited for the research and after the registration each participant was randomly assigned $(1: 1)$ to one group (treated vs control). Both groups fulfilled eight self-report questionnaires at two different timepoints. Participants in the treated group attended a 12-weeks meditation training program, which was composed of meditation classes given once a week on Wednesday starting from 6 November 2019. Participants in the control group did not receive any intervention or indication and once the experimental part was concluded, they were offered the possibility to participate in the same meditation program offered to the treated group without collecting any further information or data from them.

\subsection{Intervention}

The intervention was composed by 12 meditation classes given once a week in a designated room of the 
company office. The classes started at the end of the employee's afternoon shift and lasted approximately 1 hour each. The meditation program, named Integral Meditation (IM) is described in detail in previous studies $[16,17]$, where it has been already proved to produce benefits in psychological wellbeing among the general population.

The IM program is well accepted by both novice and experienced meditators and it is aimed to produce quick relaxation, physical wellbeing and more deeply it stimulates a sense of inner and spiritual wellbeing using simultaneous breathing, focusing attention, releasing of physical tensions, thoughts and feeling sensations through internal senses and imagery.

At the end of each meditation class, the trainer asked the participants how they feel, and they could freely share their feelings and impressions about the meditation experience. The meditation trainer has long experience in different meditation practices. He has the competencies and the skills for teaching meditation and used them to facilitate beginners quickly acquiring the techniques and feeling some benefits.

\subsection{Measures}

Each participant filled in eight self-report psychological questionnaires at two different time points: at t0 (i.e., before the start of the study) and at $\mathrm{t} 1$ (i.e., at the end of the study). In addition, baseline characteristics and lifestyle of each participant were collected through a background questionnaire.

The questionnaires investigated different psychological dimensions that, according to the literature, can be improved through meditation practice. Some of them investigate negative aspects of psychological functioning such as perceived stress, anxiety and distress that can have a detrimental effect on workers' job performance and quality of life. Other questionnaires investigate positive aspects of wellbeing such as mindfulness, self-compassion and interoception that our meditation training aims to improve and that are related to increased wellbeing. When selecting the questionnaires, the psychologist working for the company was actively involved in discussing the psychological areas that would be interesting to investigate.

CORE-OM (Clinical Outcomes in Routine Evaluation-Outcomes Measure [18] measures the global distress of the subject across different dimensions. It is a self-report questionnaire with good psychometric properties composed of 34 items aimed to measure the global distress of the subject across three dimensions: subjective wellbeing (4 items), problems/symptoms (12 items), life functioning (12 items). In addition, there are six items on risk to self and others that are not regarded as a scale but more as a clinical flag. Item score ranges from 0 to 4 . The full-scale can be read as a global index of distress, and each subscale can be used as an index of distress in its specific dimension. The higher the score the higher the distress. A decrease in the mean score after the intervention indicates a diminished global distress or diminished distress relative to the subscale. The CORE-OM possesses good psychometric properties and the same applies to the Italian version of the CORE-OM [19] used in our study.

STAI-X1 (State Trait Anxiety Inventory form X1) [20] measures state anxiety that is anxiety relating to a particular moment. While trait anxiety reflects a variable of the subject's personality, state anxiety indicates a transient emotional state of an individual in a particular space-time situation. The 20 total items are rated on a 4-point scale (1 to 4). Higher scores are associated with higher trait anxiety levels. Both the original questionnaire [21] and its Italian version [22] possess good psychometric properties.

FFMQ (Five Facet Mindfulness Questionnaire) is a 39-item multidimensional assessment tool designed to measure a person's level of dispositional mindfulness [23]. Dispositional mindfulness is a multidimensional skill distributed within the population at varying levels and it can be enhanced through mindfulness practice [24], that is the key component of MBI. FFMQ aim to measure five interrelated components of mindfulness, which are: (1) observing (3 items), (2) describing (3 items), (3) acting with awareness (3 items), (4) non-judging of inner experiences ( 3 items), (5) non-reactivity to inner experience (3 items). A higher score in the FFMQ full-scale as well as in its subscales reflects a higher level of mindfulness. The questionnaire has shown good psychometric properties both in the English and Italian version, which also shows a similar factorial structure compared to the original one [25]. A higher score after an intervention reflects an improved level of mindfulness.

PANAS (Positive Affect Negative Affect Scale) is a 20-items questionnaire that measures two general dimensions [26]: (i) positive affect (PA) reflects the level to which a person feels active, enthusiastic and alert. High PA is a state of high energy, concentration and experiencing pleasure, whereas low PA is characterized by sadness and lethargy. (ii) Negative affect (NA) is a state of general distress and 
unpleasurable engagement, with low NA reflecting calmness and serenity. This questionnaire has good psychometric properties and the Italian version [27] has been reported as a reliable and valid self-report measure.

PPS (Perceived Stress Scale) [28] measures the perception of stress and the degree to which situations in one's life are appraised as stressful. The 10 items in the PSS ask about feelings and thoughts during the last month. In each case, respondents are asked how often they felt in a certain way and the answer is given on a 5-point scale. Items were designed to tap how unpredictable, uncontrollable and overloaded respondents find their lives. Higher scores are associated with a greater stress perception. The PSS has good psychometric properties either in English and Italian versions [29].

SCS (Self-compassion scale) measures the thoughts, emotions and behaviors associated with the various components of self-compassion that simply represents compassion turned inward [30]. Neff [30] defines self-compassion as a compassionate, kind, and caring attitude toward the self when facing difficulties, painful circumstances, or personal failures. The SCS is made by 26 items that measure how often people respond to feelings of inadequacy or suffering with self-kindness, self-judgment, common humanity, isolation, mindfulness and over-identification. Responses are given on a 5-point scale from "almost never" to "almost always". Higher scores indicate more self-compassion. The SCS has good psychometric properties in the English version and similar ones in the Italian version that we have used [31].

MAIA (Multidimensional Assessment of Interoceptive Awareness) is a multidimensional questionnaire with 32 items and the answers are provided on a scale from 1 to 5 . This questionnaire investigates various aspects both positive and negative of interoception, that is the perception of one's internal state of the body. The MAIA is divided into eight sub-scales, conceptually organized into five dimensions: (a) awareness of body sensations (noticing subscale), (b) emotional reaction and attention response to sensations (non-distracting and nonworrying subscales), (c) ability to regulate attention (attention regulation subscale), (d) awareness of mind-body integration (emotional awareness, selfregulation and body listening subscales) and (e) bodily feelings of confidence (trusting subscale). Higher scores indicate a greater capacity for interception. The questionnaire possesses good psychometric properties [32]. The primary hub for interoception, the insula, is modulated by mindfulness and all other forms of meditation [33]. Interoception relies on attention and perception of internal stimuli [34-36] that are cultivated by mindfulness techniques. In fact, growing evidence indicate that a variety of contemplative practices such as meditation [37-39], mindfulness [40-43], and likely other mind-body practices enhance and improve interoception.

WEMWBS (Warwick-Edinburgh Mental Wellbeing Scale) [44] is a scale of mental wellbeing including subjective wellbeing and psychological functioning, in which all items are worded positively and address aspects of positive mental health. The 14 items of this scale measure the frequency of the subject's attitudes in a 5-point scale from 'never' to 'always'. Higher scores indicate mental wellbeing. This questionnaire has good psychometric properties valid also in its Italian version [45].

\subsection{Data analysis}

This is a two-groups pre-post experimental design. For each cohort, data were collected at two time points: at $t_{0}$, i.e., one week before the start of the program, and at $t_{1}$, i.e., a few days after the last meditation class. We did not collect data immediately after the last class to avoid confounding of immediate (but short lasting) effects.

Subjects were excluded from the analysis if they did not fill in all the questionnaires. Questionnaires were scored following the provided guidelines. Data were presented as mean \pm standard deviation (SD) for continuous variables and frequency distribution for categorical variables. Differences between the two groups (treated vs. controls) at baseline characteristics were investigated using $t$-test for continuous variables, chi-squared and Fisher's exact tests for categorical ones.

Linear mixed model effects (LME) [46] have been applied to evaluate the pre-post treatment changes on each evaluated outcome. A random intercept for each subject in the form of 1 |subject had been used to adjust all the models in order to account for intra-subject correlation produced by the two repeated measurements at $t_{0}$ and $t_{1}$ carried out on the same patients. The coefficient of the interaction time* group measures the difference in slopes between the two groups and estimates the effect of the treatment on the outcome, indicating how much more the treatment group is improving over time with respect to the investigated endpoints, compared to the control group over the same period. All the models were adjusted for 
sex and age. Analysis was performed using R 3.5.1 statistical software [47].

\section{Results}

We recruited 59 subjects and subsequently randomized them into a control $(n=29)$ and a treated $(n=30)$ group. The recruited subjects were asked to complete the questionnaires before and at the end of the meditation program. A total of 17 subjects were excluded from the analysis because they dropped out (2 subjects) or because they did not fill the questionnaires at $\mathrm{t}_{1}$ (15 subjects).

A total sample of 42 participants (13 male and 29 female) with mean age \pm standard deviation (SD) of $34.1 \pm(10.9)$ and range 20-65 were eligible for data analysis: 19 out of 42 subjects belong to the control group while 23 out of 42 to the treated group. No statistically significant differences were observed between the two groups at baseline characteristics. Further description of the study sample is provided in Table 1. In Table 2 we report the mean and SD for each questionnaire both at $t_{0}$ and $t_{1}$ separately for the control and the treated group. In order to test how the intervention influences over time each investigated psychological indicator (outcome) over the two time points, we estimated the interaction between time (pre and post) and group (treated and controls) using LME. In Table 3 we report the $\beta$ coefficient of time* treatment interaction and the corresponding $95 \% \mathrm{CI}$, and $p$-value for each questionnaire and its subscales. A statistically significant interaction between time and group means that the change in score over time differs between the two groups.

A statistically significant positive time*treatment interaction was observed in FFMQ observing subscale $(\beta=0.49,95 \% \mathrm{CI}=0.11 ; 0.47, p=0.01)$, in the whole scale of SCS $(\beta=0.47,95 \% \mathrm{CI}=0.12 ; 0.82$, $p=0.01)$ and in two out of six subscales: selfjudgment $(\beta=0.68,95 \% \mathrm{CI}=0.23 ; 1.12, p=0.004)$ and isolation $(\beta=0.66,95 \% \mathrm{CI}=0.15 ; 1.17, p=$ $0.01)$. Statistically significant results were also found in four out of eight subscales of MAIA: emotional awareness $(\beta=1.26,95 \% \mathrm{CI}=0.64 ; 1.88, p<0.001)$, self-regulation $(\beta=1.28,95 \% \mathrm{CI}=0.59 ; 1.97, p<$ $0.001)$, body listening $(\beta=1.08,95 \% \mathrm{CI}=0.39 ; 1.77$, $p<0.001)$ and trusting $(\beta=1.1,95 \% \mathrm{CI}=0.53 ; 1.67$, $p<0.001)$. Lastly, we found a statistically significant negative interaction in the PSS scale $(\beta=-3.31$, $95 \% \mathrm{CI}=-6.34 ;-0.27, p=0.034)$. and a significant positive interaction for WEMWBS questionnaire $(\beta=5.31,95 \% \mathrm{CI}=0.75 ; 9.88, p=0.02)$.
Table 1

Baseline characteristics of the analyzed sample ( controls $=19$, treated $=23$ )

\begin{tabular}{|c|c|c|c|}
\hline Variables & $\begin{array}{c}\text { Mean (SD) } \\
\text { controls }\end{array}$ & $\begin{array}{c}\text { Mean }(\mathrm{SD}) \\
\text { treated }\end{array}$ & $p$-value ${ }^{\mathrm{a}}$ \\
\hline \multirow[t]{2}{*}{ Age } & $33.53(8.15)$ & $34.65(12.56)$ & 0.73 \\
\hline & $\begin{array}{l}N(\%) \\
\text { controls }\end{array}$ & $\begin{array}{l}N(\%) \\
\text { treated }\end{array}$ & \\
\hline \multicolumn{4}{|l|}{$\overline{S e x}$} \\
\hline $\begin{array}{l}\text { Male } \\
\text { Female }\end{array}$ & $\begin{array}{c}5(26 \%) \\
14(74 \%)\end{array}$ & $\begin{array}{c}8(35 \%) \\
15(65 \%)\end{array}$ & 0.80 \\
\hline \multicolumn{4}{|l|}{ Nationality } \\
\hline $\begin{array}{l}\text { Italian } \\
\text { Non-Italian }\end{array}$ & $\begin{array}{c}18(95 \%) \\
1(5 \%)\end{array}$ & $\begin{array}{c}22(96 \%) \\
1(4 \%)\end{array}$ & 0.70 \\
\hline \multicolumn{4}{|l|}{ Marital status } \\
\hline $\begin{array}{l}\text { Cohabitant/married } \\
\text { Unmarried/single } \\
\text { Widowed }\end{array}$ & $\begin{array}{c}4(21 \%) \\
15(79 \%) \\
0(0 \%)\end{array}$ & $\begin{array}{c}10(43 \%) \\
12(52 \%) \\
1(5 \%)\end{array}$ & 0.15 \\
\hline \multicolumn{4}{|l|}{ Number of children } \\
\hline $\begin{array}{l}0 \\
1 \\
2 \\
\geq 3\end{array}$ & $\begin{array}{c}14(74 \%) \\
2(10 \%) \\
3(16 \%) \\
0(0 \%)\end{array}$ & $\begin{array}{c}16(70 \%) \\
1(4 \%) \\
5(22 \%) \\
1(4 \%)\end{array}$ & 0.76 \\
\hline \multicolumn{4}{|l|}{$\begin{array}{l}\text { Dependent } \\
\text { children/family } \\
\text { members }\end{array}$} \\
\hline $\begin{array}{l}\text { No } \\
\text { Yes }\end{array}$ & $\begin{array}{l}15(79 \%) \\
4(21 \%)\end{array}$ & $\begin{array}{c}19(83 \%) \\
4(17 \%)\end{array}$ & 1 \\
\hline \multicolumn{4}{|l|}{ Education } \\
\hline $\begin{array}{l}\text { High school } \\
\text { Degree }\end{array}$ & $\begin{array}{c}13(68 \%) \\
6(32 \%)\end{array}$ & $\begin{array}{c}17(74 \%) \\
6(26 \%)\end{array}$ & 0.96 \\
\hline \multicolumn{4}{|l|}{$\begin{array}{l}\text { Type of employment } \\
\text { agreement }\end{array}$} \\
\hline $\begin{array}{l}\text { Undetermined term } \\
\text { Fixed term }\end{array}$ & $\begin{array}{l}17(89 \%) \\
2(11 \%)\end{array}$ & $\begin{array}{l}16(70 \%) \\
7(30 \%)\end{array}$ & 0.74 \\
\hline \multicolumn{4}{|l|}{ Employee satisfaction } \\
\hline $\begin{array}{l}\text { No } \\
\text { Yes }\end{array}$ & $\begin{array}{l}14(74 \%) \\
5(31 \%)\end{array}$ & $\begin{array}{c}20(87 \%) \\
3(13 \%)\end{array}$ & 0.43 \\
\hline \multicolumn{4}{|l|}{ Sport } \\
\hline $\begin{array}{l}\text { No } \\
\text { Yes }\end{array}$ & $\begin{array}{c}9(47 \%) \\
10(53 \%)\end{array}$ & $\begin{array}{l}14(61 \%) \\
9(39 \%)\end{array}$ & 0.57 \\
\hline \multicolumn{4}{|l|}{ Smoker } \\
\hline $\begin{array}{l}\text { Yes } \\
\text { No }\end{array}$ & $\begin{array}{c}1(5 \%) \\
18(95 \%)\end{array}$ & $\begin{array}{c}6(26 \%) \\
17(74 \%)\end{array}$ & 0.11 \\
\hline \multicolumn{4}{|l|}{$\begin{array}{l}\text { Previous meditation } \\
\text { experience }\end{array}$} \\
\hline $\begin{array}{l}\text { Yes } \\
\text { No }\end{array}$ & $\begin{array}{c}3(15 \%) \\
16(85 \%)\end{array}$ & $\begin{array}{c}6(26 \%) \\
17(74 \%)\end{array}$ & 0.48 \\
\hline \multicolumn{4}{|l|}{ Religious } \\
\hline $\begin{array}{l}\text { Yes } \\
\text { No }\end{array}$ & $\begin{array}{l}13(68 \%) \\
6(32 \%)\end{array}$ & $\begin{array}{l}14(61 \%) \\
9(39 \%)\end{array}$ & 0.85 \\
\hline \multicolumn{4}{|l|}{$\begin{array}{l}\text { Member of a } \\
\text { cultural/sportive } \\
\text { association }\end{array}$} \\
\hline $\begin{array}{l}\text { Yes } \\
\text { No }\end{array}$ & $\begin{array}{c}1(5 \%) \\
18(95 \%)\end{array}$ & $\begin{array}{c}4(17 \%) \\
20(83 \%)\end{array}$ & 0.36 \\
\hline \multicolumn{4}{|l|}{$\begin{array}{l}\text { Use of biological } \\
\text { product }\end{array}$} \\
\hline Yes & $4(21 \%)$ & $6(26 \%)$ & 1 \\
\hline No & $15(79 \%)$ & $17(74 \%)$ & \\
\hline
\end{tabular}

${ }^{a} p$-value for between groups comparison. 
Table 2

Mean, Standard Deviation (SD) and internal consistency for each questionnaire and subscale in the two groups (controls and treated) at both time points $\left(\mathrm{t}_{\mathrm{o}}\right.$ and $\left.\mathrm{t}_{1}\right)$

\begin{tabular}{|c|c|c|c|c|c|c|}
\hline Questionnaire & $\begin{array}{l}\text { Mean (SD) } \\
\text { controls t0 }\end{array}$ & $\begin{array}{c}\text { Mean }(\mathrm{SD}) \\
\text { treated t0 }\end{array}$ & $\begin{array}{l}\text { Mean (SD) } \\
\text { controls t1 }\end{array}$ & $\begin{array}{c}\text { Mean }(\mathrm{SD}) \\
\text { treated t1 }\end{array}$ & $\begin{array}{c}\text { Internal } \\
\text { consistency t0 }\end{array}$ & $\begin{array}{c}\text { Internal } \\
\text { consistency t1 }\end{array}$ \\
\hline \multicolumn{7}{|l|}{ CORE-OM } \\
\hline All items & $0.89(0.37)$ & $1.00(0.57)$ & $0.90(0.38)$ & $0.82(0.39)$ & 0.92 & 0.90 \\
\hline Subjective well-being & $1.32(0.74)$ & $1.38(0.74)$ & $1.30(0.78)$ & $1.12(0.52)$ & 0.65 & 0.69 \\
\hline Life functioning & $1.01(0.38)$ & $1.13(0.63)$ & $1.09(0.38)$ & $0.94(0.51)$ & 0.80 & 0.77 \\
\hline Symptoms/problems & $1.05(0.50)$ & $1.21(0.75)$ & $0.99(0.53)$ & $0.97(0.51)$ & 0.84 & 0.82 \\
\hline Risk to self and other & $0.07(0.15)$ & $0.09(0.25)$ & $0.07(0.19)$ & $0.07(0.19)$ & 0.66 & 0.67 \\
\hline \multicolumn{7}{|l|}{ FFMQ } \\
\hline All items & $3.19(0.35)$ & $3.16(0.46)$ & $3.25(0.23)$ & $3.45(0.44)$ & 0.86 & 0.86 \\
\hline Observing & $2.94(0.73)$ & $2.97(0.73)$ & $2.84(0.58)$ & $3.36(0.58)$ & 0.81 & 0.81 \\
\hline Describing & $2.95(0.84)$ & $2.91(0.71)$ & $3.01(0.63)$ & $3.20(0.66)$ & 0.92 & 0.88 \\
\hline Acting with awareness & $3.78(0.68)$ & $3.44(0.86)$ & $3.88(0.67)$ & $3.69(0.77)$ & 0.91 & 0.92 \\
\hline Non judging of inner experience & $3.59(0.83)$ & $3.70(0.87)$ & $3.83(0.72)$ & $3.85(0.73)$ & 0.88 & 0.87 \\
\hline Non reactivity to inner experience & $2.62(0.48)$ & $2.73(0.74)$ & $2.62(0.71)$ & $3.13(0.49)$ & 0.78 & 0.81 \\
\hline \multicolumn{7}{|l|}{ MAIA } \\
\hline Noticing & $2.83(1.03)$ & $2.85(1.13)$ & $3.03(0.90)$ & $3.43(0.70)$ & 0.66 & 0.59 \\
\hline Non-distracting & $2.33(0.85)$ & $2.43(0.87)$ & $2.17(0.83)$ & $2.07(0.70)$ & 0.47 & 0.51 \\
\hline Non-worrying & $2.33(0.95)$ & $2.32(1.06)$ & $2.42(1.20)$ & $2.59(0.93)$ & 0.72 & 0.80 \\
\hline Attention regulation & $2.3(1.01)$ & $2.31(1.05)$ & $2.36(0.84)$ & $2.91(0.53)$ & 0.91 & 0.87 \\
\hline Emotional awareness & $3.22(1.24)$ & $2.87(1.26)$ & $2.92(1.16)$ & $3.82(0.61)$ & 0.91 & 0.94 \\
\hline Self-regulation & $2.35(1.17)$ & $2.13(1.12)$ & $2.30(1.15)$ & $3.36(0.82)$ & 0.88 & 0.88 \\
\hline Body listening & $2(1.13)$ & $1.75(1.2)$ & $2.05(1.17)$ & $2.88(0.66)$ & 0.86 & 0.89 \\
\hline Trusting & $3.44(1.07)$ & $2.78(1.24)$ & $3.12(1.05)$ & $3.56(0.86)$ & 0.90 & 0.91 \\
\hline \multicolumn{7}{|l|}{ PANAS } \\
\hline Positive & $3.31(0.58)$ & $3.22(0.65)$ & $3.38(0.51)$ & $3.48(0.46)$ & 0.87 & 0.78 \\
\hline Negative & $2.27(0.51)$ & $2.42(0.67)$ & $2.29(0.56)$ & $2.11(0.63)$ & 0.83 & 0.85 \\
\hline \multicolumn{7}{|l|}{ PSS } \\
\hline All items & $18.79(5.07)$ & $19.82(6.26)$ & $18.05(5.23)$ & $15.78(4.42)$ & 0.83 & 0.76 \\
\hline \multicolumn{7}{|l|}{ SCS } \\
\hline All items & $3.12(0.64)$ & $2.97(0.77)$ & $3.07(0.64)$ & $3.38(0.62)$ & 0.94 & 0.93 \\
\hline Self-kindness & $2.77(0.94)$ & $2.52(0.90)$ & $2.82(1.03)$ & $2.90(0.90)$ & 0.93 & 0.92 \\
\hline Self-judgment & $3.51(0.70)$ & $3.21(0.87)$ & $3.31(0.89)$ & $3.69(0.87)$ & 0.74 & 0.88 \\
\hline Common humanity & $2.96(0.73)$ & $2.71(0.80)$ & $2.88(1.02)$ & $3.10(0.85)$ & 0.71 & 0.81 \\
\hline Isolation & $3.61(0.99)$ & $3.49(1.14)$ & $3.38(0.76)$ & $3.92(0.71)$ & 0.87 & 0.75 \\
\hline Mindfulness & $2.86(0.98)$ & $2.86(0.76)$ & $2.79(0.83)$ & $3.10(0.71)$ & 0.82 & 0.79 \\
\hline Over identification & $3.04(0.85)$ & $3.08(1.04)$ & $3.21(0.77)$ & $3.59(0.78)$ & 0.85 & 0.74 \\
\hline \multicolumn{7}{|l|}{ WEMWBS } \\
\hline All items & $50.26(6.90)$ & $47.47(8.61)$ & $49.68(7.12)$ & $52.22(7.67)$ & 0.92 & 0.91 \\
\hline \multicolumn{7}{|l|}{ STAIX-1 } \\
\hline All items & $40.42(7.09)$ & $38.87(8.85)$ & $41.47(8.96)$ & $36.7(10.42)$ & 0.88 & 0.94 \\
\hline
\end{tabular}

SD: Standard Deviation.

We did not find any statistically significant interaction between time and treatment neither for the whole scale of CORE-OM $(\beta=-0.19,95 \% \mathrm{CI}=-0.44 ; 0.06$, $p=0.14)$ nor for its subscales. Neither in STAI $\mathrm{X}-1 \quad(\beta=-2.91 p=0.36,95 \% \mathrm{CI}=-9.20 ; 3.38)$ nor in the two subscales of PANAS (positive: $\beta=0.2$, $p=0.15,95 \% \mathrm{CI}=0.07 ; 0.47$ and negative: $\beta=-0.32$, $p=0.059,95 \% \mathrm{CI}=-0.66 ; 0.01)$ we have found a statistically significant interaction.

\section{Discussion}

The aim of our study was to evaluate the effect of our original MBI on psychological factors among a non-clinical population of adult workers using eight self-reported questionnaires. The MBI, called IM, was given after the working hours in the company's office; our IM program represents an original intervention that differs from the most common MBIs, such as Mindfulness-Based Stress Reduction. The study sample consisted of employees of a service business company based in Northern Italy; this type of worker has been less represented in MBI studies applied in workplace settings compared to others such as healthcare professionals.

In contrast with our a priori hypothesis, we did not find any significant effect of our intervention in CORE-OM, STAI X-1 and PANAS questionnaires. 
Table 3

Linear mixed model results. For each questionnaire and subscale $\beta$ coefficient of time* group interaction with its $95 \% \mathrm{CI}$, and $p$-value are reported

\begin{tabular}{|c|c|c|}
\hline Questionnaire & $\begin{array}{c}\beta \text { time* group } \\
{[95 \% \mathrm{CI}]}\end{array}$ & $p$-value \\
\hline \multicolumn{3}{|l|}{ CORE-OM } \\
\hline All items & $-0.19[-0.44 ; 0.06]$ & 0.14 \\
\hline Subjective well-being & $-0.24[-0.69 ; 0.19]$ & 0.27 \\
\hline Life functioning & $-0.27[-0.56 ; 0.02]$ & 0.07 \\
\hline Symptoms/problems & $-0.19[-0.52 ; 0.14]$ & 0.26 \\
\hline Risk to self and other & $-0.01[-0.17 ; 0.14]$ & 0.86 \\
\hline \multicolumn{3}{|l|}{ FFMQ } \\
\hline All items & $0.23[-0.02 ; 0.49]$ & 0.07 \\
\hline Observing & $0.49[0.11 ; 0.47]$ & 0.01 \\
\hline Describing & $0.24[-0.11 ; 0.58]$ & 0.17 \\
\hline Acting with awareness & $0.15[-0.24 ; 0.54]$ & 0.44 \\
\hline Non judging of inner experience & $-0.09[-0.55 ; 0.36]$ & 0.68 \\
\hline Non reactivity to inner experience & $0.40[-0.03 ; 0.84]$ & 0.07 \\
\hline \multicolumn{3}{|l|}{ MAIA } \\
\hline Noticing & $0.38[-0.15 ; 0.90]$ & 0.15 \\
\hline Non-distracting & $-0.21[-0.84 ; 0.43]$ & 0.52 \\
\hline Non-worrying & $0.18[-0.33 ; 0.71]$ & 0.47 \\
\hline Attention regulation & $0.60[-0.03 ; 1.22]$ & 0.06 \\
\hline Emotional awareness & $1.26[0.64 ; 1.88]$ & 0.0002 \\
\hline Self-regulation & $1.28[0.59 ; 1.97]$ & 0.0005 \\
\hline Body listening & $1.08[0.39 ; 1.77]$ & 0.003 \\
\hline Trusting & $1.10[0.53 ; 1.67]$ & 0.0004 \\
\hline \multicolumn{3}{|l|}{ PANAS } \\
\hline Positive & $0.20[-0.07 ; 0.47]$ & 0.15 \\
\hline Negative & $-0.32[-0.66 ; 0.01]$ & 0.06 \\
\hline \multicolumn{3}{|l|}{ PSS } \\
\hline All items & $-3.31[-6.34 ;-0.27]$ & 0.034 \\
\hline \multicolumn{3}{|l|}{ SCS } \\
\hline All items & $0.47[0.12 ; 0.82]$ & 0.009 \\
\hline Self-kindness & $0.33[-0.16 ; 0.82]$ & 0.18 \\
\hline Self-judgment & $0.68[0.23 ; 1.12]$ & 0.004 \\
\hline Common humanity & $0.47[-0.13 ; 1.07]$ & 0.12 \\
\hline Isolation & $0.66[0.15 ; 1.17]$ & 0.01 \\
\hline Mindfulness & $0.30[-0.01 ; 0.62]$ & 0.06 \\
\hline Over identification & $0.35[-0.10 ; 0.80]$ & 0.12 \\
\hline \multicolumn{3}{|l|}{ WEMWBS } \\
\hline All items & $5.31[0.75 ; 9.88]$ & 0.02 \\
\hline \multicolumn{3}{|l|}{ STAI-X } \\
\hline All items & $-2.91[-9.20 ; 3.38]$ & 0.36 \\
\hline
\end{tabular}

All models are adjusted for sex and age.

Those results indicate that our intervention did not bring clear beneficial effects on distress, state anxiety, and positive and negative affective states. Despite not being significant, among those measures we noted a trend of positive changes in the pre-post intervention in the treated compared to the control groups.

As regard to FFMQ we found a statistically significant positive time*treatment interaction only in the observing subscale while the pre-post treatment changes in the whole scale and in the remaining subscales only showed a positive association trend even if not statistically significant. Those results indicate that our intervention led to more evident changes in a specific mindfulness sub-domain. We also found a statistically significant effect of our intervention on SCS whole scale and in two of its subscales, i.e., self-judgment and isolation, indicating an increased self-compassion following the meditation program. The results relative to the MAIA indicate that our intervention helped the participants to gain a better interoceptive awareness relatively to emotional awareness, self-regulation, body listening and trusting subscales. Lastly, accordingly to the WEMWBS and PSS questionnaires analysis results, our intervention was effective in ameliorating the mental wellbeing and perceived stress among a working population that are known to be psychological factors exposed to treat in occupation settings.

Factors such as distress and anxiety represent different components of negative affect on which mindfulness intervention has been reported to have a small significant effect among different clinical populations [48]. Mindfulness intervention applied in occupational settings have been reported to induce changes in different measures of stress [5, 15], in anxiety and distress [49]. Our findings provide evidence for the hypothesis that short MBIs have a positive effect on participant's stress perception but not on anxiety and distress, despite the trend of changes in the pre-post scores might reflect a similar but not significant effect on those factors. This trend can be observed in the confidence interval of treatment effect coefficient. Those poorer results in anxiety and distress can be due to the fact that our sample constitutes a non-clinical population with no specific impairment in negative such dimensions, following that there was less room for observing an improvement in those constructs. Also, most of the research in this field have focused on healthcare professionals, who are known to be exposed to a high risk of psychological threats, while white collar workers could be less exposed to them.

On the other hand, our intervention was associated with more evident changes in different domains of positive psychological wellbeing, that are mindfulness, self-compassion and interoception.

Dispositional mindfulness, here measured through FFMQ, has been largely reported to increase following a MBI across different settings and populations; anyway [13] in their systematic review reported that MBI in workplace settings often lead to an increase only in certain subdomains of mindfulness. The intervention used in the present study led to clear beneficial effects on a mindfulness component, i.e., observing, while the other components only showed 
a consistent but not significant increase; given that, we hypothesize that a longer or a more frequent practice would lead to significant changes in additional mindfulness subdomains.

Our intervention has demonstrated to be effective in increasing self-compassion in a workplace setting. Although mindfulness meditation doesn't aim specifically to increase self-compassion, this construct is strongly related; evidences support the hypothesis that mindfulness training has a positive effect on this psychological construct [50-52] while part of the success of mindfulness-based interventions has been accounted to the cultivation of self-compassion [53].

Self-compassion, that is positively associated with personal wellbeing [54] and negatively with psychopathology [55], provides psychological and emotional resilience to cope more successfully with life challenges, including those presented at the workplace [56]. The role of self-compassion in workplace settings have been largely investigated among healthcare professionals, for whom higher levels of self-compassion are related to positive effects, such as emotional exhaustion and burnout reduction [57, 58] and increase other health and professional outcomes [59]. Similar results were found in studies that involved other kinds of employees, confirming that self-compassion has a positive impact on psychological wellbeing, job performance and job satisfaction $[60,61]$. As the modern workplace settings provide the employee with endless challenges, barriers, cognitive and emotional demands, and other difficulties $[62,63]$, the ability to cultivate comforting self-love and compassion to oneself may ultimately expand one's resources to face these workplace difficulties more effectively [61].

Another aspect of positive psychological wellbeing investigated here was interoception. Increased interoception does not always lead to a feeling of tranquility but can also trigger different uncomfortable sensations; bringing a mindful attentional style to a body scan practice can be an adaptive approach [33]. Carmody and Baer [64] found that the body scan was significantly related to the mindfulness constituents of observing and non-reactivity as well as improvements in psychological wellbeing. The results of our study are in accordance with these hypotheses, indicating that our meditation program, which involves a mindfulness body scan, was effective in increasing some sub domains of interoception, the mindfulness observing domain and the general wellbeing. The effects of our MBI on different positive aspects of wellbeing are in fact confirmed by the results in the WEMWBS questionnaire.

\section{Conclusion}

Our results support the hypothesis that MBI can promote wellbeing through different domains and those kinds of interventions can bring benefits even in working populations that are not highly exposed to stress or anxiety. Differently from the classic MBSR program, our program does not focus only stress reduction, but involves different techniques which aim to produce effect on various psychological factors, such as interoception and self-compassion. In this case the IM program has demonstrated a reduction of stress and a promotion of participants' capacity to attend to their internal state using a mindfulness approach, their self-compassion and a general increased wellbeing.

The results of our study should be interpreted taking in account some limitations. The dimension of our sample size was modest, and the participants were people who voluntarily joined the study. This might have led to a selection bias towards subjects with a higher motivation toward mindfulness training so our results cannot be extended to the population working in companies but to those who decided to do meditation. Nevertheless, the random allocation to the treated and control group protects us from bias due to confounders. Furthermore, we have only measured psychological indicators while we did not gather any information about other outcomes that are not strictly related to mindfulness meditation, such as sleep quality, prosocial behaviors at work, job performance and satisfaction. Lastly, we didn't collect follow-up measures so we can't discuss the long-term effects and the stability over times of the observed changes related to our intervention.

Our intervention has demonstrated to be effective increasing different aspects of positive wellbeing and in reducing stress among a non-clinical adult working population while it has not been significantly effective in reducing other negative psychological constructs such as distress and anxiety. This study constitutes further evidence of the beneficial effects of MBI applied in workplace settings.

\section{Author contributions}

TF and FB contributed equally as first authors. LB designed the study. TF and FB performed the 
statistical analysis. SB conducted meditation sessions. FB, TF, GB, CC, LDT and LB critically interpreted the results. All authors contributed to write the manuscript and have approved the final article.

\section{Conflict of interest}

The authors declare that the research was conducted in the absence of any commercial or financial relationships that could be construed as a potential conflict of interest.

\section{Ethical declarations}

The study was approved by the local ethics committee of the Department of Brain and behavioral Sciences (University of Pavia) (Prot. n. 024). All the participants before starting the experiment signed the written informed consent and the privacy agreement (Regulation EU 2016/679 GDPR.

All procedures performed in studies involving human participants were in accordance with the ethical standards of the institutional and/or national research committee and with the 1964 Helsinki declaration and its later amendments or comparable ethical standards. This article does not contain any studies with animals performed by any of the authors.

\section{References}

[1] Wittchen HU, Jacobi F. Size and burden of mental disorders in Europe - A critical review and appraisal of 27 studies. Eur Neuropsychopharmacol. 2005;15(4):357-76.

[2] Andlin-Sobocki P, Wittchen HU. Cost of anxiety disorders in Europe. Eur J Neurol. 2005;12(Suppl 1):39-44.

[3] Levi L. Guidance on work-related stress : spice of life or kiss of death? - European University Institute. Luxembourg, Office for Official Publications of the European Communities. 2000.

[4] Irving JA, Dobkin PL, Park J. Cultivating mindfulness in health care professionals: A review of empirical studies of mindfulness-based stress reduction (MBSR). Complement Ther Clin Pract. 2009;15(2):61-6.

[5] Heckenberg RA, Eddy P, Kent S, Wright BJ. Do workplacebased mindfulness meditation programs improve physiological indices of stress? A systematic review and meta-analysis. J Psychosom Res. 2018;114:62-71.

[6] Creswell JD. Mindfulness Interventions. Annu Rev Psychol. 2017;68(1):491-516.

[7] Forbes Human Resources Council. Council Post: Can Mindfulness Training Help Organizations Be More Effective? [Internet]. Forbes. 2017. Available from: https://www. forbes.com/sites/forbeshumanresourcescouncil/2017/05/23/ can-mindfulness-training-help-organizations-be-moreeffective/?sh=528b1f4ae1ea

[8] Oades LG, Steger MF, Fave AD, Passmore J. The Wiley Blackwell Handbook of the Psychology of Positivity and Strengths-Based Approaches at Work. The Wiley Blackwell Handbook of the Psychology of Positivity and StrengthsBased Approaches at Work. 2016.

[9] Brown KW, Ryan RM, Creswell JD. Mindfulness: Theoretical Foundations and Evidence for its Salutary Effects. Psychol Inq. 2007;18:211-37.

[10] Chiesa A, Fazia T, Bernardinelli L, Morandi G. Citation patterns and trends of systematic reviews about mindfulness. Complement Ther Clin Pract. 2017;28:26-37.

[11] Glomb TM, Duffy MK, Bono JE, Yang T. Mindfulness at work. Research in Personnel and Human Resources Management. J Pers Soc Psychol. 2018;30:115-57.

[12] Hilton LG, Marshall NJ, Motala A, Taylor SL, Miake-Lye IM, Baxi S, Shanman RM, Solloway MR, Beroesand JM, Hempel S. Mindfulness meditation for workplace wellness: An evidence map. Work. 2019;63(2):205-18.

[13] Lomas T, Medina JC, Ivtzan I, Rupprecht S, Eiroa-Orosa FJ. The impact of mindfulness on the wellbeing and performance of educators: A systematic review of the empirical literature. Teach Teach Educ. 2017;61:132-41.

[14] Virgili M. Mindfulness-Based Interventions Reduce Psychological Distress in Working Adults: a Meta-Analysis of Intervention Studies. Mindfulness (N Y). 2015;6: 326-337.

[15] Allen TD, Eby LT, Conley KM, Williamson RL, Mancini VS, Mitchell ME. What do we really know about the effects of mindfulness-based training in the workplace? Ind Organ Psychol. 2015;8(4):652-61.

[16] Fazia T, Bubbico F, Iliakis I, Salvato G, Berzuini G, Bruno S, Bernardinelli L. Short-Term Meditation Training Fosters Mindfulness and Emotion Regulation: A Pilot Study. Front Psychol. 2020;11:2828.

[17] Fazia T, Bubbico F, Salvato G, Berzuini G, Bruno S, Bottini G, Bernardinelli L. Boosting psychological well-being through a social mindfulness-based intervention in the general population. Int J Environ Res Public Health. 2020; 17(22):1-15.

[18] Evans, John Mellor-Clark, Frank Mar C. CORE: Clinical Outcomes in Routine Evaluation. J Ment Heal. 2000;9(3):247-55.

[19] Palmieri G, Evans C, Hansen V, Brancaleoni G, Ferrari S, Porcelli P, Reitano F, Rigatelli M. Validation of the Italian version of the clinical outcomes in routine evaluation outcome measure (CORE-OM). Clin Psychol Psychother. 2009;16(5):444-9.

[20] Spielberger CD. State-Trait Anxiety Inventory. In: The Corsini Encyclopedia of Psychology. John Wiley \& Sons, Inc.; 2010. p. 1-1.

[21] Spielberger CD, Gorsuch RL, Lushene RE, Vagg P, Gerard AJ, editors. Manual for the State-Trait Anxiety Inventory. CA:Consulting Psychologists; 1983.

[22] Lazzari R, Pancheri P. Questionario di valutazione dell' ansia di stato e di tratto [State-Trait Anxiety Inventory]. Organ Spec Firenze. 1980;

[23] Baer RA, Smith GT, Hopkins J, Krietemeyer J, Toney L. Using Self-Report Assessment Methods to Explore Facets of Mindfulness. Assessment. 2006;13(1):27-45.

[24] Tomlinson ER, Yousaf O, Vitters $\varnothing$ AD, Jones L. Dispositional Mindfulness and Psychological Health: a Systematic Review. Mindfulness (N Y). 2018;9:23-43. 
[25] Giovannini C, Giromini L, Bonalume L, Tagini A, Lang M, Amadei G. The Italian Five Facet Mindfulness Questionnaire: A Contribution to its Validity and Reliability. J Psychopathol Behav Assess. 2014;36(3):415-23.

[26] Crawford JR, Henry JD. The Positive and Negative Affect Schedule (PANAS): Construct validity, measurement properties and normative data in a large non-clinical sample. $\mathrm{Br}$ J Clin Psychol. 2004;43(3):245-65.

[27] A T, RR M, Jr CP. Factorial and construct validity of the Italian Positive and Negative Affect Schedule (PANAS). Eur J Psychol Assess. 2003;19(2):131-41.

[28] Cohen S, Kamarck T, Mermelstein R. A global measure of perceived stress. J Health Soc Behav. 1983;24(4):385-96.

[29] Mondo M, Sechi C, Cabras C. Psychometric evaluation of three versions of the Italian Perceived Stress Scale. Curr Psychol. 2019;1-9.

[30] Neff KD. The Development and Validation of a Scale to Measure Self-Compassion. Self Identity. 2003;2:223-50.

[31] Veneziani CA, Fuochi G, Voci A. Self-compassion as a healthy attitude toward the self: Factorial and construct validity in an Italian sample. Pers Individ Dif. 2017;119: 60-8.

[32] Calì G, Ambrosini E, Picconi L, Mehling WE, Committeri $\mathrm{G}$. Investigating the relationship between interoceptive accuracy,interoceptive awareness, and emotional susceptibility. Front Psychol. 2015;6:1202.

[33] Gibson J. Mindfulness, Interoception, and the Body: A Contemporary Perspective. Front Psychol. 2019;10:2012.

[34] Mehling WE, Price C, Daubenmier JJ, Acree M, Bartmess E, Stewart A. The Multidimensional Assessment of Interoceptive Awareness (MAIA). PLoS One. 2012;7(11):e48230.

[35] Bornemann B, Herbert BM, Mehling WE, Singer T. Differential changes in self-reported aspects of interoceptive awareness through 3 months of contemplative training. Front Psychol. 2015;5:1504.

[36] García-Cordero I, Esteves S, Mikulan EP, Hesse E, Baglivo FH, Silva W, García M del C, Vaucheret E, Ciraolo C, García HS, Adolfi F, Pietto M, Herrera E, Legaz A, Manes F, García AM, Sigman M, Bekinschtein TA, Ibáñez A, Sedeño L. Attention, in and out: Scalp-level and intracranial EEG correlates of interoception and exteroception. Front Neurosci. 2017;11:411.

[37] Lazar SW, Kerr CE, Wasserman RH, Gray JR, Greve DN, Treadway MT, McGarvey M, Quinn BT, Dusek JA, Benson $\mathrm{H}$, Rauch SL, Moore CI, Fischl B. Meditation experience is associated with increased cortical thickness. Neuroreport. 2005;16(17):1893-7.

[38] Hölzel BK, Ott U, Gard T, Hempel H, Weygandt M, Morgen $\mathrm{K}$, Vaitl D. Investigation of mindfulness meditation practitioners with voxel-based morphometry. Soc Cogn Affect Neurosci. 2008;3(1):55-61.

[39] Kang DH, Jo HJ, Jung WH, Kim SH, Jung YH, Choi CH, Lee US, An SC, Jang JH, Kwon JS. The effect of meditation on brain structure: Cortical thickness mapping and diffusion tensor imaging. Soc Cogn Affect Neurosci. 2013;8(1): 27-33.

[40] Farb NAS, Segal Z V., Mayberg H, Bean J, Mckeon D, Fatima Z, Anderson AK. Attending to the present: Mindfulness meditation reveals distinct neural modes of selfreference. Soc Cogn Affect Neurosci. 2007;2(4):313-22.

[41] Farb N, Daubenmier J, Price CJ, Gard T, Kerr C, Dunn BD, Klein AC, Paulus MP, Mehling WE. Interoception, contemplative practice, and health. Front Psychol. 2015;6:763.

[42] Farb NAS, Segal Z V., Anderson AK. Mindfulness meditation training alters cortical representations of interoceptive attention. Soc Cogn Affect Neurosci. 2013;8(1): 15-26.

[43] Haase L, Thom NJ, Shukla A, Davenport PW, Simmons AN Stanley EA, Paulus MP, Johnson DC. Mindfulness-based training attenuates insula response to an aversive interoceptive challenge. Soc Cogn Affect Neurosci. 2015;11(1): 182-90.

[44] Tennant R, Hiller L, Fishwick R, Platt S, Joseph S, Weich S, Parkinson J, Secker J, Stewart-Brown S. The Warwick-Dinburgh mental well-being scale (WEMWBS): Development and UK validation. Health Qual Life Outcomes. 2007;5:63.

[45] Gremigni P, Stewart-Brown S. Measuring mental wellbeing: Italian validation of the Warwick-Edinburgh Mental Well-Being Scale (WEMWBS). G Ital di Psicol. 2011;38(2):485-505.

[46] Pinheiro JC, Bates DM. Mixed-effects models in S and SPLUS. Springer; 2000

[47] R Development Core Team. R: a language and environment for statistical computing. Vienna, Austria R Found Stat Comput [Internet]. 2017; Available from: http://www.rproject.org/

[48] Goyal M, Singh S, Sibinga EMS, Gould NF, RowlandSeymour A, Sharma R, Berger Z, Sleicher D, Maron DD, Shihab HM, Ranasinghe PD, Linn S, Saha S, Bass EB, Haythornthwaite JA. Meditation programs for psychological stress and well-being: A systematic review and meta-analysis. JAMA Intern Med. 2014;174(3):357-68.

[49] Bartlett L, Martin A, Neil AL, Memish K, Otahal P, Kilpatrick M, Sanderson K. A systematic review and metaanalysis of workplace mindfulness training randomized controlled trials. J Occup Health Psychol. 2019;24(1): 108-26.

[50] Birnie K, Speca M, Carlson LE. Exploring self-compassion and empathy in the context of mindfulness-based stress reduction (MBSR). Stress Heal. 2010;26(5):359-71.

[51] Lee WK, Bang HJ. The effects of mindfulness-based group intervention on the mental health of middle-aged Korean women in community. Stress Heal. 2010;26(4):341-8.

[52] Rimes KA, Wingrove J. Pilot study of mindfulness-based cognitive therapy for trainee clinical psychologists. Behav Cogn Psychother. 2011;39(2):235-41.

[53] Kuyken W, Watkins E, Holden E, White K, Taylor RS, Byford S, Evans A, Radford S, Teasdale JD, Dalgleish T. How does mindfulness-based cognitive therapy work? Behav Res Ther. 2010;48(11):1105-12.

[54] Zessin U, Dickhäuser O, Garbade S. The Relationship Between Self-Compassion and Well-Being: A Meta-Analysis. Appl Psychol Heal Well-Being. 2015;7(3):340-64.

[55] MacBeth A, Gumley A. Exploring compassion: A metaanalysis of the association between self-compassion and psychopathology. Clin Psychol Rev. 2012;32(6):545-52.

[56] Neff KD, Knox MC. Self-Compassion. In: Encyclopedia of Personality and Individual Differences. Cham: Springer International Publishing; 2017. p. 1-8.

[57] Dev V, Fernando AT, Lim AG, Consedine NS. Does selfcompassion mitigate the relationship between burnout and barriers to compassion? A cross-sectional quantitative study of 799 nurses. Int J Nurs Stud. 2018;81:81-8.

[58] Hashem Z, Zeinoun P. Self-Compassion Explains Less Burnout Among Healthcare Professionals. Mindfulness (N Y). 2020;1-10.

[59] Raab K. Mindfulness, Self-Compassion, and Empathy Among Health Care Professionals: A Review of the Literature. J Health Care Chaplain. 2014;20(3):95-108. 
[60] Abaci R, Arda D. Relationship between Self-compassion and Job Satisfaction in White Collar Workers. Procedia Soc Behav Sci. 2013;106:2241-7.

[61] Reizer A. Bringing self-kindness into the workplace: Exploring the mediating role of self-compassion in the associations between attachment and organizational outcomes. Front Psychol. 2019;10:1148.

[62] Giorgi G, Arcangeli G, Perminiene M, Lorini C, ArizaMontes A, Fiz-Perez J, Di Fabio A, Mucci N. Work-related stress in the banking sector: A review of incidence, correlated factors, and major consequences. Front Psychol. 2017;8:2166.
[63] Achnak S, Griep Y, Vantilborgh T. I am so tired. How fatigue may exacerbate stress reactions to psychological contract breach. Front Psychol. 2018;

[64] Carmody J, Baer RA. Relationships between mindfulness practice and levels of mindfulness, medical and psychological symptoms and well-being in a mindfulness-based stress reduction program. J Behav Med. 2008;31(1):23-33. 